Gut, 1989, 30, 1544-1551

\title{
Effect of sucralfate on gastric mucosal blood flow in rats
}

\author{
B W CHEN, W M HIU, S K LAM, C H CHO, M M T NG, AND C T LUK \\ From the University Departments of Medicine and Pharmacology, University of Hong Kong, Queen Mary \\ Hospital, Hong Kong
}

Summary Sucralfate possesses site protective and cytoprotective actions and heals ulcers effectively, but its effect on gastric mucosal blood flow is unknown. Using an ex vivo gastric chamber preparation, we studied the effect of sucralfate on gastric mucosal blood flow in rats by laser doppler flowmetry. Under both fasting and fed states, measurements of gastric mucosal blood flow and damage were made in rats after topical application of absolute ethanol alone or after pretreatment with sucralfate. Gastric mucosal damage was assessed by measuring the total area of haemorrhagic mucosal lesions. Ethanol induced gastric mucosal lesions were significantly less with sucralfate pretreatment than without $(\mathbf{p}<\mathbf{0} \cdot 008)$. Mucosal blood flow significantly fell after ethanol application $(p<0 \cdot 001)$. The fall was significantly less in fed than in fasted rats $(p<0 \cdot 05)$, and after pretreatment with sucralfate $100 \mathrm{mg}$ or $200 \mathrm{mg}$ than without in both fasted $(p<0.0008$ and 0.00001 , respectively) and fed $(p<0.002$ and 0.001 , respectively) rats. Graded doses of sucralfate $(25-400 \mathrm{mg})$ resulted in an increase in gastric mucosal blood flow in a dose dependent manner $(r=0.731, p<0 \cdot 001)$. In conclusion that sucralfate increases gastric mucosal blood flow in rats and lessens the fall in blood flow in rats treated with ethanol, and this action may contribute to its protection against the vascular damage of mucosa by ethanol.

Sucralfate is an aluminium salt of sucrose sulphate and has proved to be effective for the treatment of duodenal ulcer, ${ }^{1-3}$ gastric ulcer, ${ }^{+h}$ and recently to improve chronic antral gastritis. ' It protects the gastric mucosa of rats against deep necrotising injury of ethanol, an injury considered to be caused by

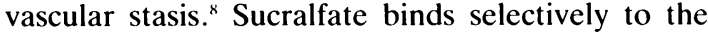
base of peptic ulcer" and protects the gastric mucosa from pepsin, acid and bile. "It has also been shown to have cytoprotective properties by stimulating the release of prostaglandins and mucus, and by accelerating the renewal of epithelial cells." It is unknown, however, whether sucralfate has any effect on gastric mucosal blood flow; this forms the basis of the present study.

\section{Methods}

PREPARATION OF RAT STOMACH

Male Sprague-Dawley rats weighing 250-300 g were

Address for correspondence: Prof S K Lam, MD, University Department of Medicine, Queen Mary Hospital, Pokfulam Road, Hong Kong.

Accepted for publication 7 March 1989. used for the study. The animals were housed in an air conditioned room in which temperature was maintained at $22(1)^{\circ} \mathrm{C}$ and humidity at $65-70 \%$. They were fed a standard pellet diet (Ralston Purina Co, Chicago, USA). A gastric chamber preparation was used, as described previously. ${ }^{2}$ In brief, the animals were anaesthetised with sodium pentobarbital (Abbott, $50 \mathrm{mg} / \mathrm{kg}$ intraperitoneal) and kept warm with a heating lamp. Their trachea was cannulated and a midline laparotomy was carried out. The stomach was exposed and its pylorus and the cardiac end were ligated with linen thread before performing subdiaphragmatic vagotomy. The organ was then drawn up through a central oval aperture in a plexiglass platform placed immediately above the animal and opened along the greater curvature. The stomach was spread out, mucosal surface uppermost, on the platform. An ex vivo gastric chamber was thus made, with the major vasculature being left intact. The glandular mucosa in the chamber was first washed with three changes of deionised water.

Gastric mucosal damage was induced by topical application of $1.5 \mathrm{ml}$ of $100 \%$ ethanol. 
MEASUREMENT OF GASTRIC MUCOSAI. BI.OOD FLOW

Gastric mucosal blood flow was measured by the laser doppler flow technique. ${ }^{1314}$ The laser doppler flowmeter (Periflux, Sweden) was used to record the gastric mucosal blood flow with the detector placed $0.5 \mathrm{~mm}$ above and perpendicular to the mucosal surface. Blood flow measurement was made at the glandular part of the stomach, $0.5 \mathrm{~cm}$ from the junction between the fore and glandular part of the stomach and on the lesser curvature. Because blood flow measurements were found to vary in different regions of the stomach, all measurements in this study, with the exception of the validation experiments against the hydrogen clearance method (vide infra), were made at the above site. The zero value was defined by placing the laser probe against a white board. Each blood flow measurement was performed with a frequency of $4 \mathrm{kHz}$ and a time constant of $1.5 \mathrm{sec}$. The area of laser-emission of the probe was $1 \mathrm{~mm}^{2}$. The validity of the measurement of blood flow by laser doppler technique was verified by two methods. First, measurements of blood flow were made before and after occlusion of the blood supply by clamping the coeliac trunk, and after release of clamping. Blood flow dropped to zero when clamping was applied and returned to its initial level when the clamp was released. Second, blood flow measurement was further validated by the hydrogen clearance method described by Murakami. ${ }^{15}$ Blood flow was measured at the same spot on the glandular part of the stomach using the laser doppler flowmetry and followed by the hydrogen clearance method. Seventy six pairs of readings were recorded at four random locations adjacent to the lesser curve in each stomach of 19 rats and correlation between the two methods was made.

After a stabilising period of 30 minutes, the first reading of gastric mucosal blood flow was recorded and was taken as the basal blood flow. Subsequent readings of blood flow were expressed as percentages of the basal blood flow and were taken at 15 minute intervals for 90 minutes. The laser doppler technique thus measures the relative gastric mucosal blood flow. To verify that the recording was reproducible, four consecutive readings were measured at the same point in the stomach within five minutes.

MEASUREMENT OF THE ULCER INDEX

Ulcer index was measured by the total area of macroscopic haemorrhagic necrosis on the glandular stomach taken 15 minutes after the last measurement of blood flow at 90 minutes. This was obtained by tracing the areas of ulceration on a transparency, projected onto a graph paper with squares of $1 \mathrm{~mm} \times 1 \mathrm{~mm}$, and counting the total area.
Blood flow measurement:

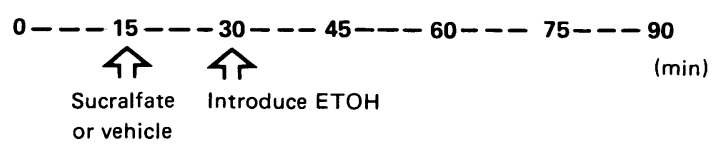

Fig. 1 Sequences of steps taken to measure gastric mucosal blood flow and the administration of alcohol, deionised water, sucralfate and its control.

IEXPERIMENTAL PROTOCOI.

Sucralfate (sucralfate granules, Chugai Pharmaceutical, Japan) was mixed in a suspension with methylcellulose. The suspensions with various sucralfate concentrations or their control solutions were added 15 minutes after the first blood flow measurement (Fig. 1). Methycellulose was used as the base because sucralfate formed a more stable and homogeneous suspension with methylcellulose than with deionised water. Ethanol or its control solution was added after another 15 minutes (Table 1). Eight

Table Experimental protocol for the study of ulcer index and the mucosal blood flow

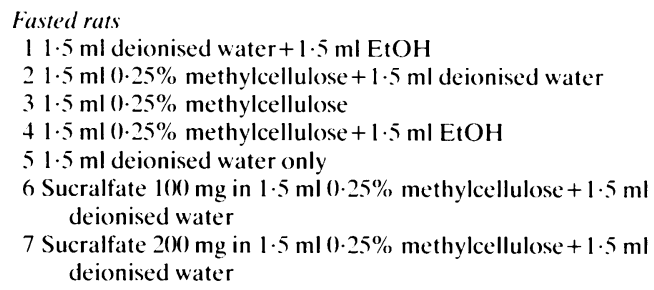

8 Sucralfate $100 \mathrm{mg}$ in $1.5 \mathrm{ml}(0.25 \%$ methylcellulose $+1.5 \mathrm{ml} \mathrm{EtOH}$

9 Sucralfate 20() $\mathrm{mg}$ in $1.5 \mathrm{ml}(0.25 \%$ methylcellulose $+1.5 \mathrm{ml} \mathrm{EtOH}$ 10 Sucralfate $200 \mathrm{mg}$ in 1.5 deionised water $+1.5 \mathrm{ml} \mathrm{EtOH}$

\section{Fed rats}

$1 \quad 1.5 \mathrm{ml} 0.25 \%$ methylcellulose $+1.5 \mathrm{ml} \mathrm{EtOH}$

$21.5 \mathrm{ml}(0.25 \%$ methylcellulose $+1.5 \mathrm{ml}$ deionised water

3 Sucralfate $100 \mathrm{mg}$ in $1.5 \mathrm{ml}(0.25 \%$ methylcellulose $+1.5 \mathrm{ml} \mathrm{EtOH}$

4 Sucralfate $200 \mathrm{mg}$ in $1.5 \mathrm{ml}(0.25 \%$ methylcellulose $+1.5 \mathrm{ml} \mathrm{EtOH}$

Dose response study

Without ethanol

The following doses of sucralfate in $1.5 \mathrm{ml}(0.25 \%$ methylcellulose were used in fasted rats ( 5 rats for each dose)
$125 \mathrm{mg}$
$2.50 \mathrm{mg}$
$3100 \mathrm{mg}$
$4200 \mathrm{mg}$
$5 \quad 400 \mathrm{mg}$

With ethanol

Ulcer index and mucosal blood flow were studied in fasted rats treated with ethanol as above and pretreated with the following doses of sucralfate ( 8 rats for each dose)

$1 \quad 25 \mathrm{mg}$

$2 \quad 50 \mathrm{mg}$

$3400 \mathrm{mg}$

$\mathrm{EtOH}=$ absolute alcohol 
rats were used for each experiment except for the dose response study on sucralfate and blood flow, in which five rats were used for each group. The concentrations of the active and control reagents were detailed in Table 1. Experiments were performed in fasted and fed rats. Fasted rats were fasted for 24 hours and fed rats were allowed to eat freely until they were anaesthetised. The dose response studies were performed on fasted rats.

STATISTICALANALYSIS

Gastric mucosal blood flow was plotted against time and three parameters were derived: the peak flow rate at 30 minutes after $0 \mathrm{~min}$ recording, the slope of the gastric mucosal blood flow (after log transformation) against time from 30 to 90 minutes, and the area under the curve, an arbitrary summation flow over time $(\Sigma F)$ from 0 to 90 minutes. Comparisons were made between groups, using Student's $t$ test..$^{15}$ Ulcer index was compared using the same method. A dose response curve of $\Sigma F$ against different doses of sucralfate was plotted, and linear correlation was performed..$^{15}$

\section{Results}

\section{ULCER INDEX}

\section{Control rats}

Rats given deionised water only, methylcellulose only, or combination of deionised water and methylcellulose showed no mucosal ulceration.

\section{Effect of diluent on ethanol damage}

Rats pretreated with methylcellulose alone showed no significant difference in ethanol induced ulceration from those pretreated with deionised water alone (Fig. 2). Sucralfate given with methylcellulose as the base showed no significant difference in ulcer index when compared with sucralfate given with deionised water.

\section{Effect of sucralfate on ethanol damage}

Rats pretreated with sucralfate $200 \mathrm{mg}$ in deionised water or methylcellulose showed significantly less $(p<0.008)$ ethanol induced ulceration than those pretreated with deionised water or methylcellulose alone (Fig. 2). Sucralfate $100 \mathrm{mg}$ or $400 \mathrm{mg}$ in methylcellulose also significantly protected the mucosa from ethanol injuries. At doses of $25 \mathrm{mg}$ and $50 \mathrm{mg}$, however, there were no significant differences in the ulcer indices when compared with rats pretreated with methylcellulose alone. There was no significant difference in ulcer index amongst the three groups of rats given sucralfate $100 \mathrm{mg}, 200 \mathrm{mg}$, and $400 \mathrm{mg}$ respectively.
Effect of feeding on ethanol damage

Fed rats treated with ethanol had a lower ulcer index compared with fasted rats, but the difference did not reach statistical significance. When pretreated with sucralfate $100 \mathrm{mg}$ or $200 \mathrm{mg}$ there was no significant difference in the ulcer index between the fasted and fed rats (Fig. 2). In the fed state, ulcer index was significantly lower in rats pretreated with sucralfate $200 \mathrm{mg}(\mathrm{p}<0 \cdot 05)$ but not with $100 \mathrm{mg}(\mathrm{p}>0 \cdot 1)$.

BLOOD FLOW

\section{Laser doppler recording}

Stable recording was obtained throughout each experiment and a steady electrical baseline of the laser doppler flow was obtained. The coefficient of variation in blood flow was $2.4 \%$ for four recordings in the same rat and $6.2 \%$ for the baseline recording between rats $(n=112)$.

\section{Comparison of $\mathrm{H}_{2}$-clearance method and laser doppler flowmetry for the measurement of gastric mucosal blood}

The blood flow measured by the laser doppler flow showed a significant direct correlation with that recorded with the hydrogen clearance method $(\mathrm{r}=0.91, \mathrm{p}<0.001)$ (Fig. 3).

\section{Effect of the vehicle}

In rats treated with deionised water instead of ethanol, there was no significant difference in blood flow in rats bathed in methylcellulose compared with those bathed in deionised water (Fig. 4).

\section{Effect of sucralfate}

Gastric mucosal blood flow, expressed as the summation flow, significantly decreased $(p<0 \cdot 001)$ in rats treated with ethanol but not so in rats treated with deionised water (Fig. 4). In rats treated with ethanol, gastric mucosal blood flow, both the summation flow and peak flow at 30 minutes, were significantly higher in those pretreated with sucralfate $100 \mathrm{mg}$ ( $\mathrm{p}<0.0008$ and $<0.00001$ respectively) and $200 \mathrm{mg}$ (both $\mathrm{p}<0.00001$ ) than in those without sucralfate pretreatment (Fig. 4). There were no significant differences in the summation and peak flows $(\mathrm{p}<0.15$ and 0.92 respectively) between sucralfate $100 \mathrm{mg}$ and sucralfate $200 \mathrm{mg}$. The slope of fall in blood flow was significantly smaller with sucralfate $100 \mathrm{mg}$ and $200 \mathrm{mg}$ than with methylcellulose alone $(\mathrm{p}<0.05,0.02$ respectively).

\section{Effect of feeding}

In the ethanol experiments, fed rats compared with fasted rats had significantly higher mucosal blood flow, irrespective of whether the mucosa had been 


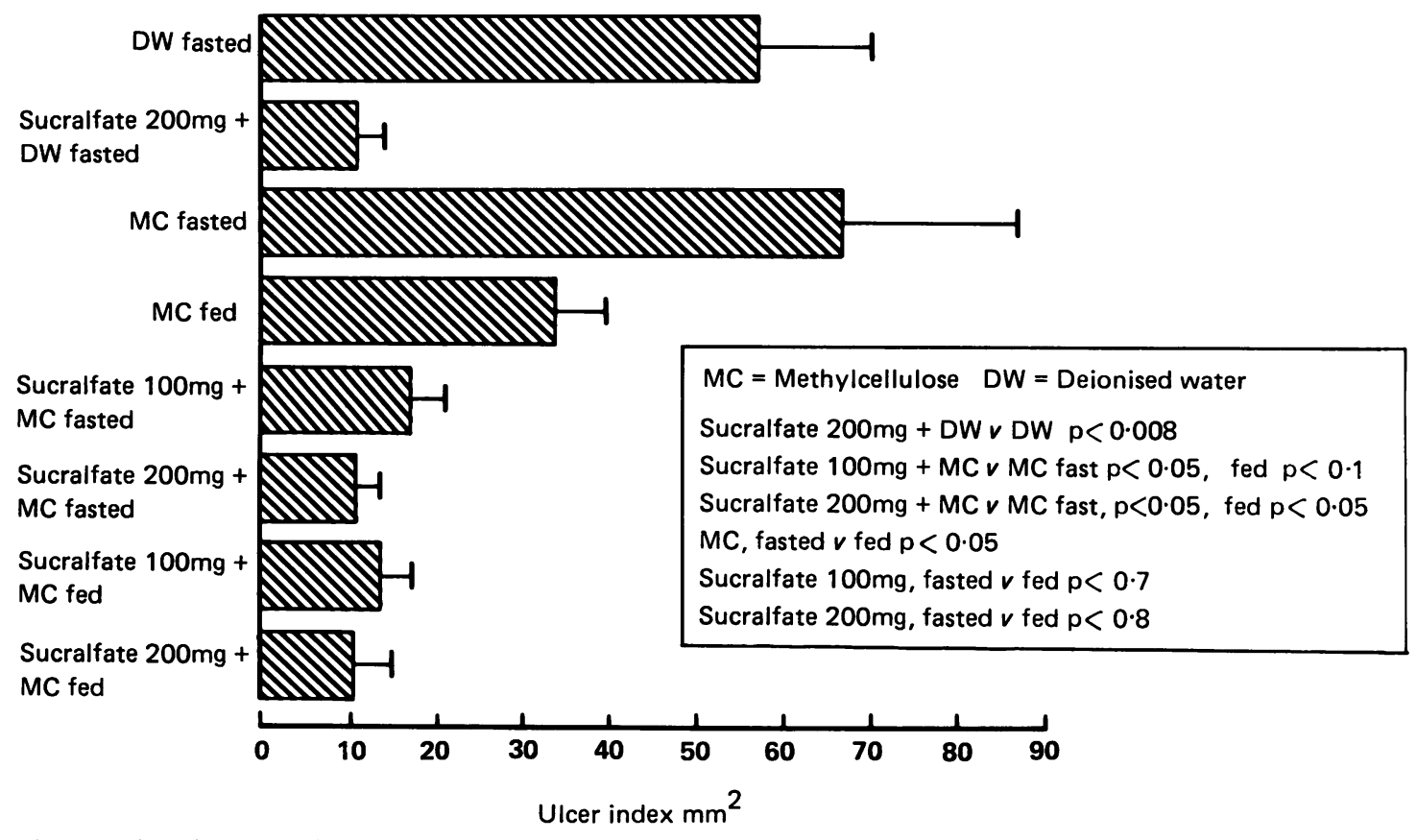

Fig. 2 Ethanol induced ulcer index in rats with and without sucralfate pretreatment. The ulcer index was significantly lower in rats pretreated with sucralfate $100 \mathrm{mg}$ or $200 \mathrm{mg}$ than those without pretreatment. Feeding did not significantly affect ulcer index.

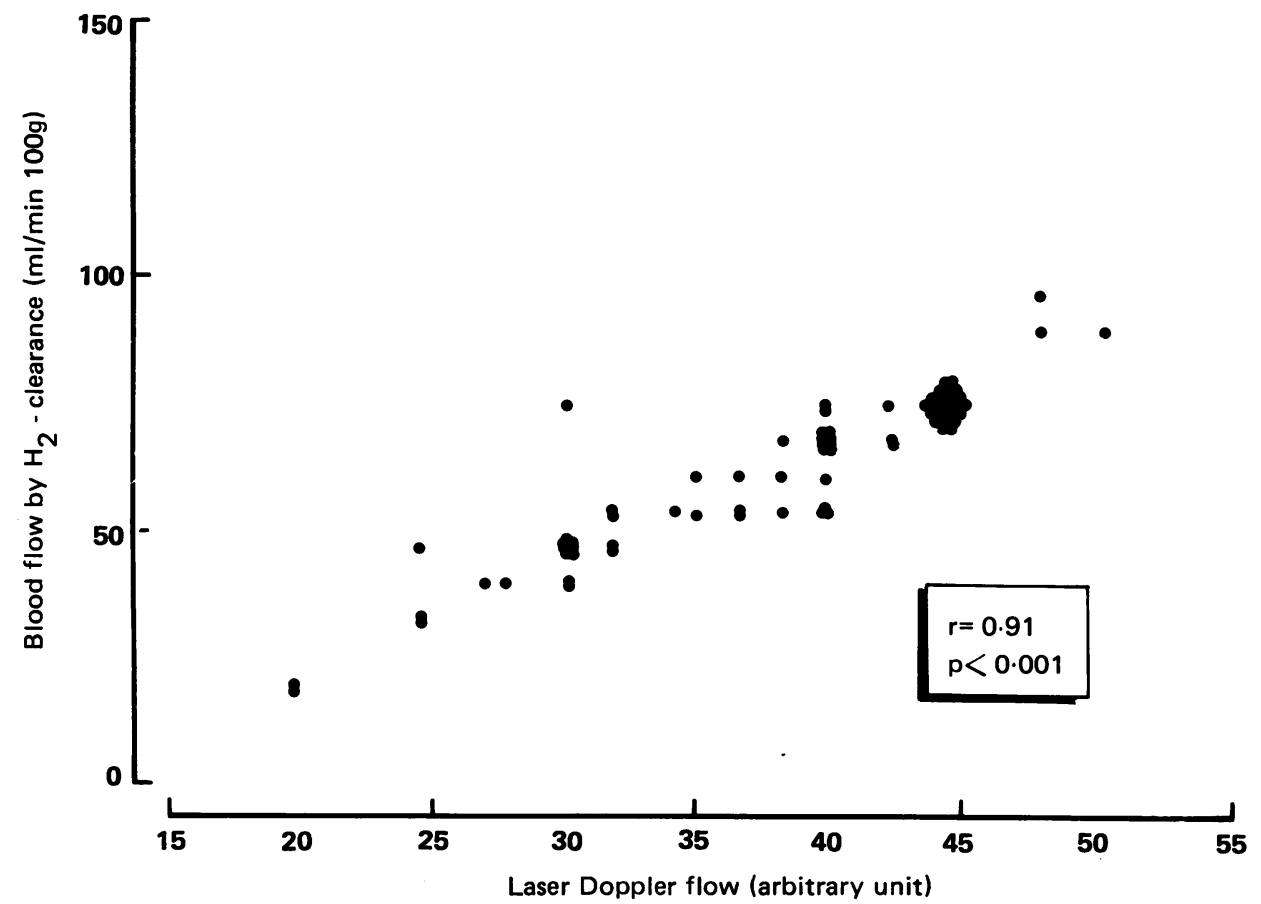

Fig. 3 Relationship between blood flow measured by $\mathrm{H}_{2}$-clearance method and laser doppler flowmetry in glandular part of the stomach in rats. Blood flow measured by laser doppler flowmetry showed a direct correlation $(r=0.91, p<0.001)$ with the blood flow measured by $\mathrm{H}_{2}$ clearance method. 


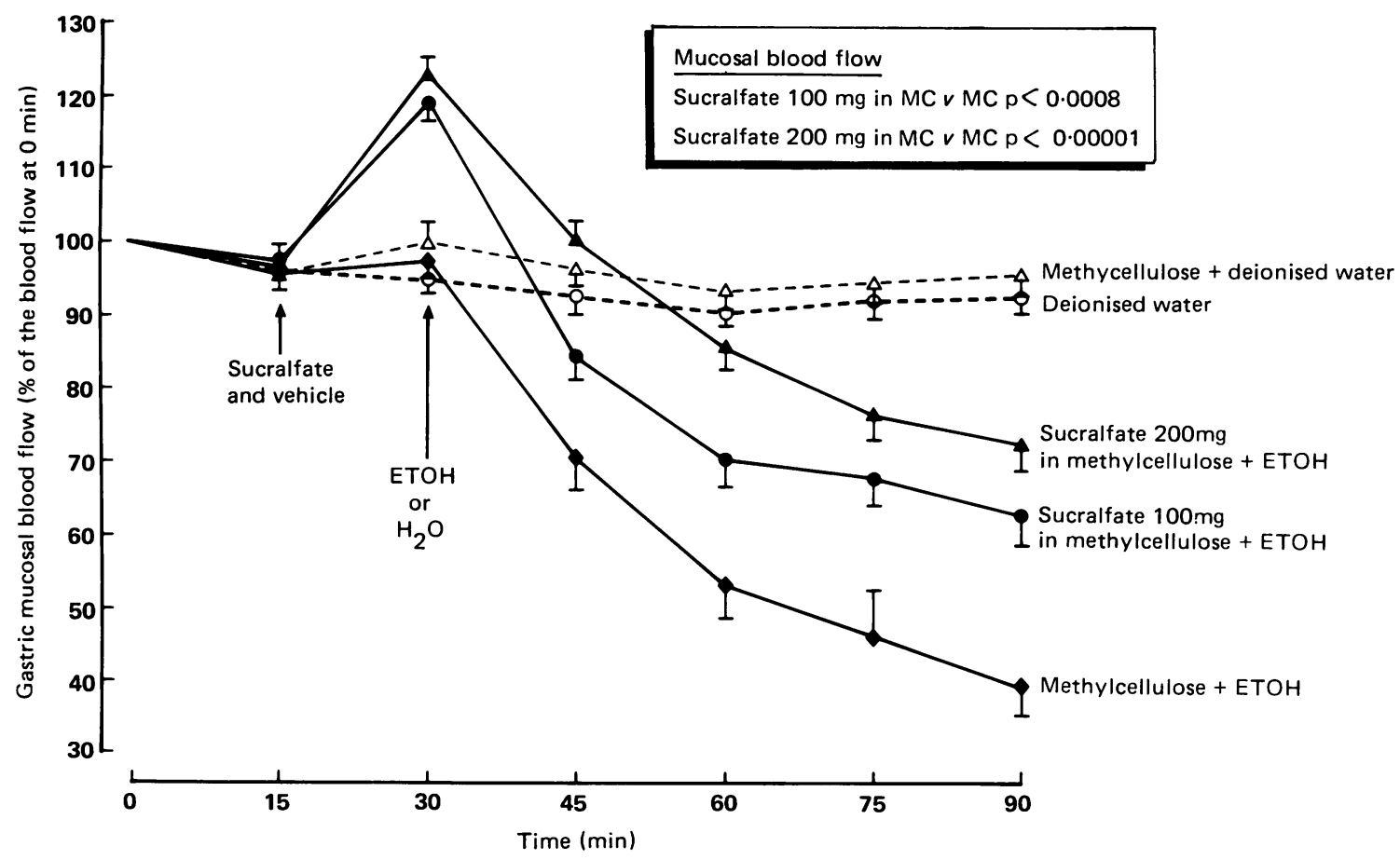

Fig. 4 Effect of sucralfate on gastric mucosal blood flow in fasted rats treated with ethanol (EtOH) or deionised water $\left(\mathrm{H}_{2} \mathrm{O}\right)$. Summation flow and peak flow (at $30 \mathrm{~min}$ ) were significantly higher in rats pretreated with sucralfate $100 \mathrm{mg}$ or $200 \mathrm{mg}$ than in those without sucralfate pretreatment. There was no significant difference in the summation flow but not peak flow with sucralfate $200 \mathrm{mg}$ than $100 \mathrm{mg}$.

pretreated with methylcellulose, sucralfate $100 \mathrm{mg}$ or sucralfate $200 \mathrm{mg}$ as measured by the summation flow (Fig. 5, p $<0.05,0.002,0.005$ respectively) but not for peak flow at 30 minutes. Fed rats pretreated with either dose of sucralfate had significantly higher summation blood flow ( $p<0.002,0.001$ respectively) or peak flow at 30 minutes (both $\mathrm{p}<0.00001$ ) compared with rats not pretreated with sucralfate. The slope of fall in blood flow after ethanol was not significantly different in fasted and fed rats irrespective of whether or not they are pretreated with sucralfate $100 \mathrm{mg}, 200 \mathrm{mg}$.

\section{DOSAGE OF SUCRALFATE}

\section{Without ethanol}

Blood flow increased and reached a peak $15 \mathrm{~min}(30$ min from zero time) after treatment with all doses of sucralfate given $(25 \mathrm{mg}, 50 \mathrm{mg}, 100 \mathrm{mg}, 200 \mathrm{mg}$, and $400 \mathrm{mg}$ ). Thereafter it dropped and approached basal value 75 minutes after treatment (within $8 \%$ of the basal blood flow). A significant linear relationship was observed between sucralfate dosage and gastric mucosal blood flow as measured by both the summation flow $(\mathrm{r}=0.732, \mathrm{p}<0 \cdot(0) 1$, Fig. 6) and the peak flow that occurred at 30 minutes $(r=0.783$, $\mathrm{p}<0 \cdot(001)$.

\section{With ethanol}

The slope of fall in blood flow after sucralfate $100 \mathrm{mg}$ was significantly smaller than that after $25 \mathrm{mg}$ $(p<0.001)$ and $50 \mathrm{mg}(\mathrm{p}<0.001)$ but was not significantly different from that after $200 \mathrm{mg}$ and $400 \mathrm{mg}$.

\section{Discussion}

When ethanol was applied to the gastric mucosa, it induced acute mucosal congestion and ulceration. ${ }^{171 \mathrm{~s}}$ This was accompanied by mucosal vascular stasis with a decrease in mucosal blood flow as shown by the laser doppler ${ }^{19}$ and the hydrogen clearance techniques." These findings agree well with our observations that ethanol led to significant mucosal ulcerations in the rat stomach and to a significant fall in gastric mucosal blood flow as measured by the laser doppler technique. 


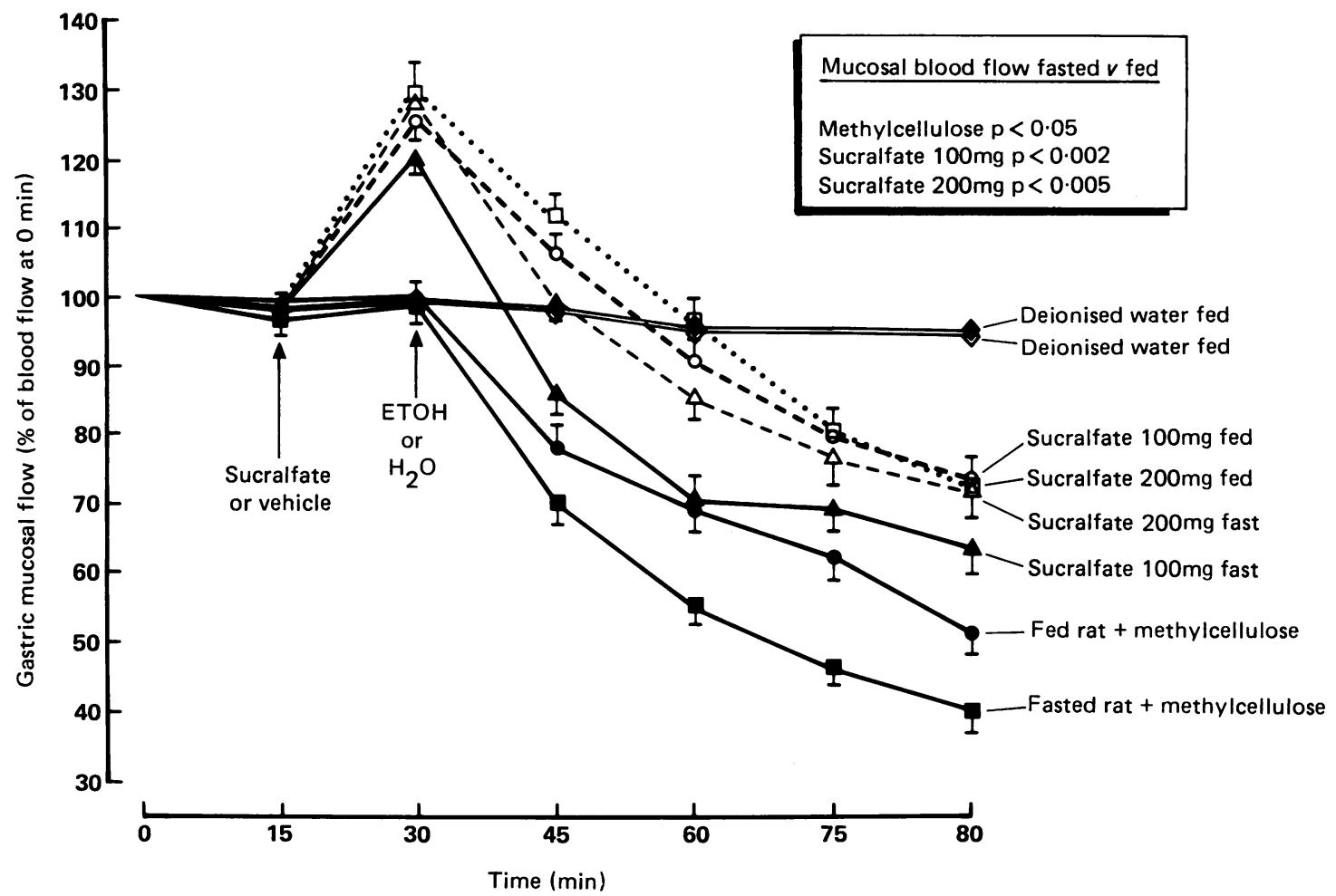

Fig. 5 Effect of feeding on gastric mucosal blood flow in rats treatment with ethanol. Both summation flow, and peak flow at 30 minutes flow, was significantly higher in fed than fasted rats pretreated with methylcellulose, sucralfate $100 \mathrm{mg}$ or $200 \mathrm{mg}$.

Our results also confirmed those of others that sucralfate pretreatment prevented gastric mucosal damage by ethanol. ${ }^{.122}$ Sucralfate has been shown to bind to normal gastric mucosa, although the affinity is less compared with its affinity for the ulcer base. ${ }^{x}$ Sucralfate has also been shown recently to have cytoprotective properties. It releases prostaglandins,,$^{2.25}$ stimulates mucus production ${ }^{23}$ and bicarbonate secretion, ${ }^{25}$ and promotes epithelial cell renewal $^{23}$ from the normal mucosa of rats. The mechanisms by which sucralfate protects gastric mucosa from ethanol injury remain unknown. It has been suggested that the morphologic, histologic, ultrastuructural, and functional features of sucralfate induced gastric mucosal protection are indistinguishable from those induced by prostaglandins $\mathrm{s}^{2 \mathrm{t}}$ and by arachidonic acid, the precursor of prostaglandins. ${ }^{27}$

Interestingly, we observed that pretreatment with sucralfate lessened the fall in gastric mucosal blood flow that accompanied ethanol treatment. This is a result of two components of action. First, sucralfate pretreatment led to an initial rise in blood flow. In

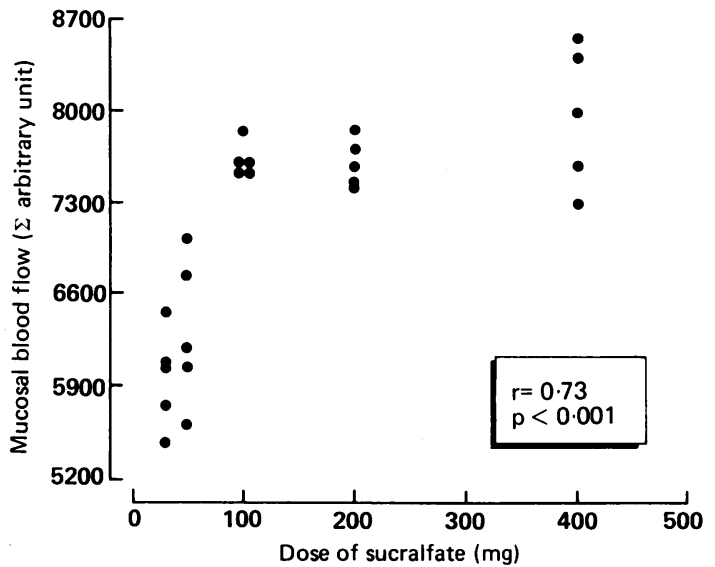

Fig. 6 Interrelationship between gastric mucosal blood flow and dose of sucralfate $(25 \mathrm{mg}, 50 \mathrm{mg}, 100 \mathrm{mg}, 200 \mathrm{mg}$, and $400 \mathrm{mg}$ ). The gastric mucosal blood flow was expressed as the product of the flux value and time (represented as total area under the graph). A direct correlation $(t=0.73 p<0.0001)$ was observed between gastric mucosal blood flow and dose of sucralfate. A similar correlation $(r=0.85 p<0.001)$ was observed when the blow flow values were log transformed. 
fact, in rats not treated with ethanol, sucralfate increased gastric mucosal blood flow in a dosedependent manner (Fig. 6). This helped to counter balance the subsequent fall after ethanol, as evident by the significantly greater summation flow with sucralfate pretreatment. Second, the slope of the fall after ethanol was significantly less with sucralfate pretreatment than without. This suggested that sucralfate helped to maintain a better blood flow in the face of the ethanol induced fall in blood flow.

It is not known from the present study whether sucralfate induced increase in mucosal blood flow is dependent on prostaglandin. Although several studies showed that exogenous prostaglandins increased basal gastric mucosal blood flow, ${ }^{2 \times-31}$ recent studies using non-antisecretory doses of 16,16dimethyl prostaglandin $E_{2},{ }^{32}$ which successfully prevented ethanol induced gastric mucosal injuries, failed to show any increase in mucosal blood flow. Furthermore, although misoprostol, a synthetic prostaglandin $E_{1}$ derivative, appeared to prevent ethanol induced gastric mucosal injuries, ${ }^{33}$ it did not increase gastric mucosal blood flow. ${ }^{3+}$ These studies suggest that cytoprotection by prostaglandins does not require an increase in mucosal blood flow as a prerequisite.

The effect of feeding is of interest. Feeding itself appeared to decrease the amount of mucosal damage by ethanol, although the difference did not reach statistical significance. Feeding, however, significantly lessened the fall in gastric mucosal blood flow as induced by ethanol, although feeding itself did not increase the blood flow (Fig. 5). Feeding also augmented the effect of $100 \mathrm{mg}$ and $200 \mathrm{mg}$ sucralfate in lessening ethanol induced fall in blood flow, as evident by the significantly higher summation flow compared with that in the fasting state, although the slopes of the fall did not differ. Our findings suggested that feeding might have a small but significant contribution to mucosal protection by helping to maintain the gastric mucosal blood flow.

It remains unknown whether improvement in mucosal blood flow per se, either by enhancement or maintenance of flow, confers cytoprotection to gastric mucosa exposed to exogenous or ischaemic injuries. It is tempting to speculate that an improvement in gastric mucosal blood flow may improve the transport of nutrients and bicarbonates to the surface epithelium. ${ }^{35}$ It is also conceivable that an improvement in mucosal blood flow should contribute towards cytoprotection in situations where ischaemia plays an important pathophysiological role, such as restraint induced stress lesions in rats, ${ }^{36}$ and stress lesions in the critically ill patients ${ }^{37}$ It remains also unclear whether improvement in mucosal blood flow contributes towards ulcer healing. An increase in mucosal blood flow at the edge of the healing gastric ulcer has been shown in man. ${ }^{3 .}$

This study was supported by the Peptic Ulcer Research Fund (311/041/0372) of the University of Hong Kong. The authors are grateful to M Chan for secretarial assistance. Abstract of paper presented at the Annual Scientific Meeting of the American Gastroenterological Association meeting, New Orlean, 1988. Prof Chan was visiting scientist from the First Teaching Hospital, Beijing Medical College, Beijing, China.

\section{References}

1 Hentschel E. Schutze K. Dufek W. Controlled comparison of sucralfate and cimetidine in duodenal ulcer. Scand J Gastroenterol 1983; 18 (suppl 83): 31-5.

2 Hollander D. Efficacy of sucralfate for duodenal ulcers. A multicenter, double-blind trial. J Clin Gastroenterol 1981; 3 (suppl 12): 153-7.

3 Lam SK, Hui WM, Lau WY, et al. Sucralfate overcomes adverse effect of cigarette smoking on duodenal ulcer healing and prolongs subsequent remission. Gastroenterology 1987; 92: 1193-201.

4 Lam SK, Lau WY, Lai CL, et al. Efficacy of sucralfate in corpus, prepyloric and duodenal ulcer-associated gastric ulcer. Am J Med 1985; 79 (suppl 2C): 24-31.

5 Lahtinen J, Aukee S, Miettinen P, Poikolainen E, Paakkonen M, Sandstrom R. Sucralfate and cimetidine for gastric ulcer. Scand J Gastroenterol 1983; 18 (suppl 83): 49-51.

6 Martin F, Farley A, Gagnon M, Poitras P, Bensemana D. Short-term treatment with sucralfate or cimetidine in gastric ulcer. Scand J Gastroenterol 1983: 83 (suppl): 37 41.

7 Hui WM, Lam SK, Ho J, et al. Sucralfate vs cimetidine for the treatment of duodenal-ulcer associated gastritis [Abstract]. Gastroenterology 1987; 92: 1442.

8 Lacy ER, Ito S. Ethanol-induced insult to the surface rat gastric perithelium: a study of damage and repair. In: Allen A. Flemstrom G, Gamer A. Silen W. Turnberg LA, eds. Mechanism of mucosal protection in the upper gastrointestinal tract. New York: Raven Press, 1984: 4955.

9 Nakazawa S, Nagashima R, Samloff IM. Selective binding of sucralfate to gastric ulcer in man. Dig Dis $S_{c i}$ 1981; 26: 297-300.

10 Nagashima R. Hirano T. Selective binding of sucralfate to ulcer lesion. 1. Experiments in rats with acetic acidinduced gastric ulcer receiving unlabelled sucralfate. Arzneimittelforsch 1980; 30: 80-3.

11 Quadros E, Ramsamoo JE, Wilson DE. Role of mucus and prostaglandins in the gastric mucosal protective actions of sucralfate against ethanol-induced injury in the rat. Am J Med 1987; 83 (suppl 3B): 19-23.

12 Mersereau WA. Hinchey EJ. Effect of gastric acidity on gastric ulceration induced by hemorrhage in the rat, utilizing a gastric chamber technique. Gastroenterology 1973; 64: 1130-5. 
13 Henrik A. Lindhagen J, Nilsson GE. Salerud EG, Jodal M. Lundgren O. Evaluation of Laser Doppler Flowmetry in the assessment of intestinal blood flow in cat. Gastroenterology 1985: 88: 951-7.

14 Kvernebo K. Lunde OC. Stranden E. Larsen. Human gastric blood circulation evaluated by endoscopic laser doppler flowmetry. Scand J Gastroenterol 1986: 21: 68592.

15 Murakami M. Moriga M. Miyake T. Uchino H. Contact electrode method in hydrogen gas clearance technique: A new method for determination of regional gastric mucosal blood flow in animals and humans. Gastroenterology 1982: 82: 457-67.

16 Snedecor CW. Cochran WG. Statistical methods. 6th ed. Ames, lowa: Iowa State University Press, 1967.

17 Lacy ER. Ito S. Microscopic analysis of ethanol damage to rat gastric mucosa after treatment with a prostaglandin. Gastroenterology 1982: 83: 619-25.

18 Ohno T. Ohtsuki H, Okabe S. Effects of 16,16-dimethyl prostaglandin E2 on ethanol-induced and aspirininduced gastric damage in the rat. Gastroenterology 1985; 88: 353-61.

19 Pihan G, Majzoubi D. Haudenschild C. Trier JS, Szabo Sandor. Early microcirculatory stasis in acute gastric mucosal injury in the rat and prevention by 16,16 dimethyl prostaglandin E2 or sodium thiosulfate. Gastroenterology 1986; 91: 1415-26.

20) Leung FW. Robert A. Guth PH. Gastric mucosal blood flow in rats after administration of 16,16-dimethyl prostaglandin E2 at a cytoprotective dose. Gastroenterology 1985; 88: 1948-53.

21 Nagashima R, Hoshino E, Hinohara Y, Sakai K, Haa S, Nakano H. Effect of sucralfate on ethanol-induced gastric mucosal damage in the rat. Scand J Gastroentrol 1988: 18 (suppl 83): 17-20.

22 Hollander D. Tarnawski A, Krause WJ, Gergely H. Protective effect of sucralfate against alcohol-induced gastric mucosal injury in the rat. Gastroenterology 1985; 88: $366-74$.

23 Tarnawski A, Hollander D, Krause WJ, Zipser RD, Stachura J. Gergely H. Does sucralfate affect the normal gastric mucosa? Gastroenterology 1986; 90: 893905.

24 Ligumsky M, Karmeli F, Rachilewitz D. Sucralfate stimulation of gastric $\mathrm{PGE}_{2}$ synthesis - possible mechanism to explain its effective cytoprotective propertics [Abstract]. Gastroenterology 1984; 86: 1164.

25 Crampton JR, Gibbons LC. Rees WDW. Effects of sucralfate on gastro-duodenal bicarbonate secretion and prostaglandin $\mathrm{E}_{2}$ metabolism. Am J Med 1987; 83 (suppl 3B): 14-8.

26 Tarnawski A. Hollander D. Stachura J, Krause WJ. Gergely $\mathrm{H}$. Prostaglandin protection of the rat gastric mucosa against alcohol injury - a dynamic time-related process. The role of the mucosal proliferative zone. Gastroenterology 1985: 88: 3.34-52.

27 Tarnawski A, Hollander D, Stachura J, Krause WJ. Arachidonic acid protection of gastric mucosa against alcohol injury: sequential analysis of morphologic and functional changes. J Lab Clin Med 1983; 102: 34()-51.

28 Robert A. An intestinal discase produced experimentally by a prostaglandin deficiency. Gastroenterology 1975; 69: 1045-7.

29 Robert A. Antisecretory, antiulcer, cytoprotective and diarrheogenic properties of prostaglandins. In: Samuelsson B. Paoletti R, eds. Advances in prostaglandin and thromboxane research. Vol. 2. New York: Raven, 1976: 507-20.

30 Robert A. Nezamis JE. Lancaster C. Hanchar AJ. Cytoprotection by prostaglandins in rats: prevention of gastric necrosis produced by alcohol. $\mathrm{HCl}, \mathrm{NaOH}$, hypertonic $\mathrm{NaCl}$, and thermal injury. Gastroenterology 1979; 77: 433-43.

31 Robert A. Cytoprotection by prostaglandins. Gastroenterology 1979; 77: 761-7.

32 Leung FW, Andre Robert, Guth PH. Gastric mucosal blood flow in rats after administration of 16,16-dimethyl prostaglandin $\mathrm{E}_{2}$ at a cytoprotective dose. Gastroenterology 1985; 88: 1948-53.

33 Bauer RF. Bianchi RG, Casler J, Goldstin B. Comparative mucosal protective properties of misoprostol, cimetidine, and sucralfate. Dig Dis Sci 1986; 31 (suppl): 81S-85S.

34 Leung FW. Miller JC, Guth PH. Dissociated effects of misoprostol on gastric acid secretion and mucosal blood flow. Dig Dis Sci 1986; 31 (suppl): 86S-90S.

35 Gannon B, Browning J, O’Brien P, et al. Mucosal microvascular architecture of the fundus and body of human stomach. Gastroenterology 1984; 86: 866-75.

36 Murakami M, Lam SK. Inada M. Miyake T. Pathophysiology and pathogenesis of acute gastric mucosal lesions following hypothermic restraint stress in rats. Gastroenterology 1985; 88: 660-5.

37 Mengy R. The prophylaxis of stress ulceration. N Engl J Med 1980; 302: 461-2.

38 Takenobu K, Sunao K, Nobuhiro S, Masuki F, Hideyuki F, Hiroshi A. Gastric mucosal blood distribution and its changes in the healing process of gastric ulcer. Gastroenterology 1983; 84: 1541-6. 